\title{
The Bile Acid Membrane Receptor TGR5: A Valuable Metabolic Target
}

\author{
Thijs W.H. Pols Lilia G. Noriega Mitsunori Nomura Johan Auwerx \\ Kristina Schoonjans
}

Laboratory of Integrative and Systems Physiology at the Ecole Polytechnique Fédérale de Lausanne, Lausanne, Switzerland

\section{Key Words}

Metabolism • Bile acids • Nuclear receptors · TGR5 •

G-protein-coupled receptor

\begin{abstract}
Bile acids (BAs) are amphipathic molecules that facilitate the uptake of lipids, and their levels fluctuate in the intestines as well as in the circulation depending on food intake. Besides their role in dietary lipid absorption, BAs function as signaling molecules that activate specific $B A$ receptors and trigger downstream signaling cascades. The BA receptors and the signaling pathways they control are not only important in the regulation of $\mathrm{BA}$ synthesis and their metabolism, but they also regulate glucose homeostasis, lipid metabolism and energy expenditure - processes relevant in the context of the metabolic syndrome. In addition to the function of the nuclear receptor $F X R \alpha$ in regulating local effects of BAs in the organs of the enterohepatic axis, increasing evidence points to a crucial role of the G-protein-coupled receptor TGR5 in mediating systemic actions of BAs. Here we review the current knowledge on $B A$ receptors, with a strong focus on the cell membrane receptor TGR5, which has emerged as a promising target for intervention in metabolic diseases.
\end{abstract}

Copyright @ 2011 S. Karger AG, Basel

\section{KARGER}

Fax +4161306 1234

E-Mail karger@karger.ch

www.karger.com
(C) 2011 S. Karger AG, Basel

Accessible online at: www.karger.com/ddi

\section{Introduction}

Bile acids (BAs) are a component of bile, which also contains phosphatidylcholine, bilirubin and cholesterol. Through their detergent properties, which allow the emulsification of lipids, BAs facilitate the uptake of lipids together with the fat-soluble vitamins $\mathrm{A}, \mathrm{D}, \mathrm{E}$ and $\mathrm{K}$ from the intestine [1]. BAs also control the intestinal microbial flora and play a role in the elimination of cholesterol from the body $[2,3]$. More recently, BAs are increasingly being appreciated as signaling molecules that inform cells and organs concerning the fasting/feeding state, thereby regulating processes ranging from BA and lipid metabolism to glucose and energy homeostasis $[4,5]$. This metabolic function is in fact not too surprising given their central role in dietary lipid absorption. We review here the most recent developments in the field of BA signaling, and the potential pharmaceutical repercussions in using them to treat various facets of the metabolic syndrome.

\section{Signaling Pathways Activated by BAs}

\section{Nuclear Receptor Signaling Pathways}

The farnesol X receptor (FXR) is a nuclear receptor (NR) that controls BA homeostasis. The FXR cDNA was first cloned from both mouse and rat in $1995[6,7]$. Rodents have two FXR family members, FXR $\alpha$ and FXR $\beta$. 
Fig. 1. a Representation of signaling pathways that are modulated by BAs. Genomic and nongenomic actions of BAs are mediated by NRs and GPCRs. The BAs that modulate the activity of the receptor are indicated in the arrows and sorted by decreasing potency (left: high, right: low). Arrows in dark grey indicate agonistic actions, white indicates antagonistic/inhibitory actions and light grey indicates a modulatory effect, either agonistic or antagonistic. Receptors for which only a limited number of BAs were tested are indicated with dashed arrows. ${ }^{*}$ Only conjugated forms of LCA and deoxycholic acid (DCA) are reported to activate the muscarinic receptors. FPR $=$ Formyl-peptide receptor. b Simplified overview of the TGR5signaling pathway leading to downstream signaling via cAMP induction. $\mathrm{AC}=\mathrm{Ad}-$ enylate cyclase.

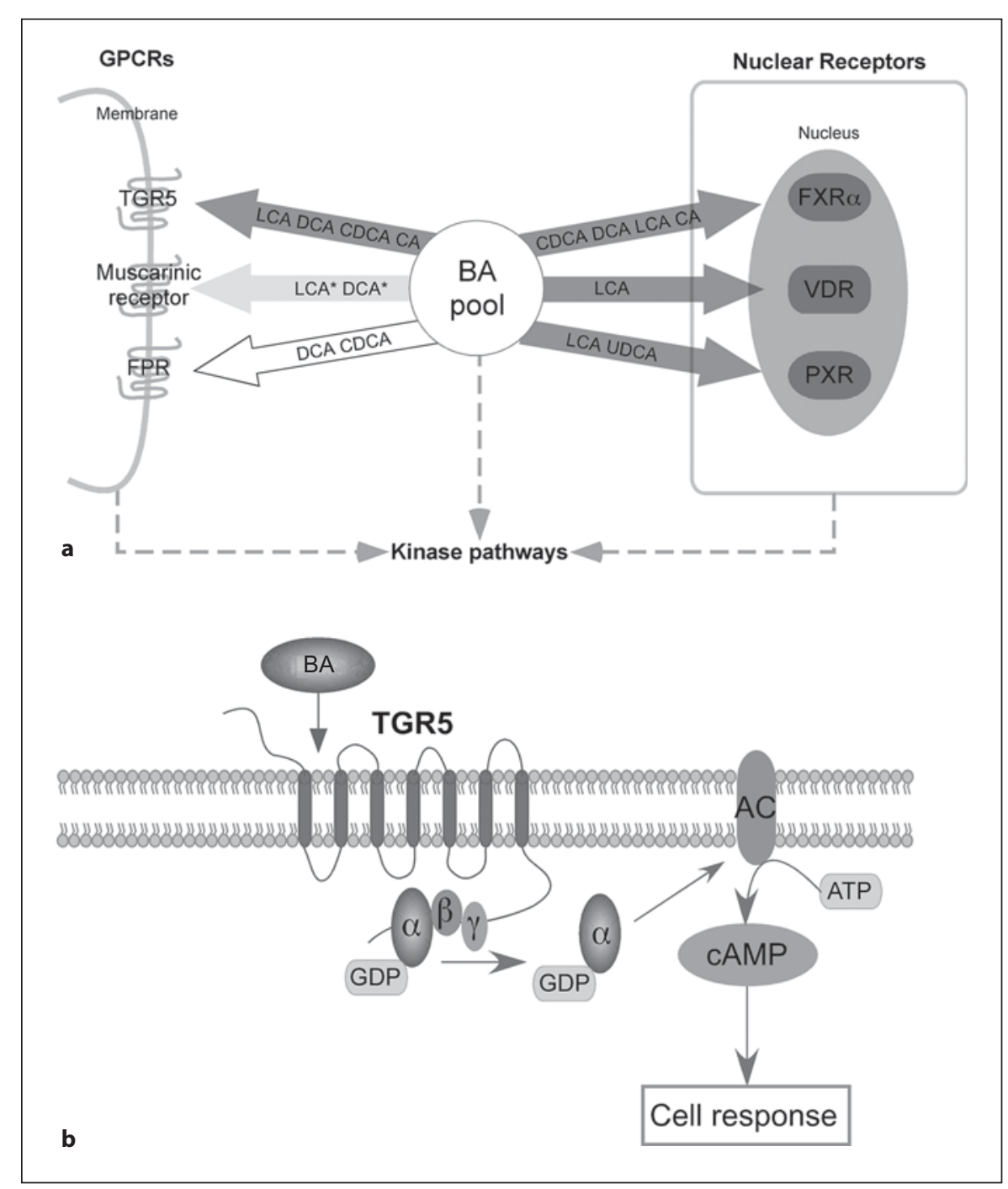

In humans only $\mathrm{FXR} \alpha$ is expressed, although $\mathrm{FXR} \beta$ is still present in the genome as a nonexpressed pseudogene. FXR $\alpha$ is most potently activated by conjugated or unconjugated forms of chenodeoxycholic acid (CDCA) with an $\mathrm{EC}_{50}$ in the range of $4.5-10 \mu \mathrm{M}$ [8-10], while FXR $\beta$ in mice is activated by lanosterol, an intermediate of BA synthesis [11].

In addition to $\mathrm{FXR} \alpha$, other NRs directly activated by lithocholic acid (LCA) are the pregnane X receptor (PXR) and the vitamin D receptor (VDR) [12-14] (fig. 1a). PXR is not only activated by LCA, but also by certain BA precursors, such as $7 \alpha-\mathrm{OH}-4$-cholesten-3-one [15]. PXR is like FXR $\alpha$ expressed in the liver and intestine $[12,13]$. One of the physiological functions of PXR is to induce phase I detoxification through induction of CYP3A, which explains the finding that PXR transgenic mice are protected against LCA-induced liver toxicity in a model of cholestasis [12]. Like PXR, VDR plays a role in the detoxification of BAs through induction of CYP3A [14]. In addition to their roles in detoxifying BAs, both NRs inhibit BA synthesis. Activation of VDR by vitamin D inhibits BA synthesis via the FGF19-CYP7A1 pathway [16], and activation of PXR with rifampicin, an agonist of hPXR, inhibits BA synthesis through a pathway involving $\mathrm{HNF} 4 \alpha$ [17]. It should be noted that high concentrations of LCA (30-100 $\mu \mathrm{M})$ are required to activate VDR and PXR, bringing into question the physiological relevance of the direct regulation of their activity by BAs.

Kinase Signaling Pathways Regulated by BAs

BAs also modulate kinase signaling pathways, such as the JNK pathway, which also downregulate CYP7A1 [18]. 
Another study has coupled JNK activation indirectly to BAs as the mechanism of the FGF19-FGFR4 signaling pathway to suppress CYP7A1 [19]. In addition to JNK, the p38 mitogen-activated protein kinases, the extracellular signal-regulated kinase (ERK) pathway and Akt are activated by BAs $[20,21]$. Although the precise mechanisms remain elusive, a study indicated that phosphorylation of ERK1, ERK2 and Akt by BAs is induced through both radical oxygen species-dependent and G-protein-coupled receptor (GPCR)-dependent, pathways [21]. The activation of these phosphorylation cascades by BAs is, besides the suppression of CYP7A1, also involved in the regulation of apoptosis and cytoprotective effects [20, 22]. It is also tempting to speculate that some of these signaling pathways may contribute to the enhanced lifespan observed in yeast exposed to BAs, as yeast lack both the nuclear and membrane BA receptors [23].

\section{GPCR Signaling Pathways Modulated by BAs}

Most relevant to this review is that BAs also bind and modulate the activity of specific GPCRs (fig. 1a). The GPCR family comprises over 800 receptors, divided into 3 subgroups [24]. There are currently 3 GPCRs known that are modulated by BAs. Based on their sequence, these BA-modulated GPCRs are classified as class A or in the rhodopsin-like receptor class, the largest subgroup of GPCRs. Although BAs modulate the activity of muscarinic receptors (also designated as acetylcholine receptors) $[25,26]$ and inhibit the activity of formyl-peptide receptors $[27,28]$, the GPCR that has been most studied in relation to BAs is TGR5, also known as M-BAR, GPBAR or GPR131 [29, 30]. TGR5 is encoded by a singleexon gene, and its conservation among vertebrates underlines its physiological importance [29]. TGR5 is activated by several BAs, with LCA being the most potent natural agonist with an $\mathrm{EC}_{50}$ of $0.53 \mu \mathrm{M}[29,30]$. Other BAs that activate TGR5 include conjugated and unconjugated forms of deoxycholic acid, CDCA and cholic acid with an $\mathrm{EC}_{50}$ of 1.0, 4.4 and $7.7 \mu \mathrm{M}$, respectively [30].

TGR5 is abundantly expressed in gallbladder epithelium $[31,32]$ and in the intestine, particularly in the ileum and colon $[29,31,33]$. Also human spleen as well as human mononuclear and CD14+ white blood cells express high amounts of TGR5 [30]. TGR5 was also present in rabbit spleen and rabbit alveolar macrophages [30]. TGR5 is detected in several liver cells, including rat liver sinusoidal endothelial cells, as well as in rat Kupffer cells, which are resident macrophages of the liver [34, 35]. Furthermore, TGR5 is expressed in BAT, skeletal muscle and selected areas of the central nervous system [36, 37].

\section{The BA Receptor TGR5}

\section{TGR5 in BA Homeostasis and Metabolism}

In resting conditions, GPCRs, including TGR5, are in a so-called low-affinity state. In response to binding of BAs to the ligand-binding pocket of the receptor, a complex is released from TGR 5 consisting of G-protein- $\alpha_{s},-\beta$ and $-\gamma[24,30]$. GDP is subsequently released from the G-protein and replaced by GTP, leading to dissociation of the G-protein complexes into G-protein- $\alpha_{s}$ and $-\beta \gamma$ dimers. G-protein- $\alpha_{s}$ then activates adenylyl cyclase inducing cAMP production, and the subsequent activation of protein kinase $\mathrm{A}$, and its downstream signaling pathways [30] (fig. 1b). Whether TGR5 may also bind to other G-proteins, which have distinct downstream effector molecules, is still unresolved [24].

To explore the biological role of TGR5, several groups have independently generated $\mathrm{TGR} 5^{-1-}$ mice $[31,33,38]$. Interestingly, the total BA pool size in $\mathrm{TGR} 5^{-/-}$mice was decreased [33], which was also observed by our lab (J.A. and K.S., unpubl. data). Why the BA pool decreases in TGR $5^{-/-}$mice is currently unknown, but appears independent of changes in fecal BA excretion [33]. In addition to changes in the BA pool size, $\mathrm{TGR}^{-/-}$mice fed a lithogenic diet are protected against cholesterol gallstone formation [39]. Hydrophobic bile salts decrease gallbladder smooth muscle function potentially via stimulation of TGR5, which could be a contributing factor in the manifestation of gallstone disease [40]. Additionally, TGR5 is expressed in human cholangiocytes and plays a role in bile composition, via the induction of chloride secretion in gallbladder epithelial cells $[32,41]$. Taken together, the physiological changes observed in mice lacking TGR5 with regard to BA homeostasis together with expression of TGR 5 in human tissue relevant to BA homeostasis hint towards a role of TGR 5 in bile formation and homeostasis in man $[32,41]$.

\section{Effect of TGR5 on Body Weight}

TGR5 activation reduces the body weight of mice fed a high-fat diet. We first demonstrated that dietary supplementation of BAs significantly reduces body weight gain in C57Bl/6J mice fed a high-fat diet [36]. Cholic acid administration completely prevented high-fat diet-induced changes in adipose mass and morphology, and reversed 120 days of diet-induced weight gain, without apparent toxicity [36]. The weight-reducing effects were not due to reduced caloric intake, but were the consequence of enhanced energy expenditure. Using deiodinase-2-deficient mice, the effect of cholic acid on energy expenditure 
was shown to require the induction of deiodinase-2 through a TGR5-cAMP-mediated pathway that was active in murine BAT and in human skeletal muscle myoblasts. Importantly, this effect of BAs on energy expenditure was independent of FXR, as the FXR agonist GW4064, did not increase cAMP levels in BAT and increased diet-induced obesity in mice. Deiodinase-2 increases mitochondrial oxidative phosphorylation and energy expenditure in brown adipose tissue and muscle via the conversion of inactive thyroxine (T4) into active 3,5,3'-tri-iodothyronine (T3), which activates the thyroid receptor and thereby induces energy expenditure [36]. This effect was subsequently confirmed using the semisynthetic BA, 6-ethyl-23(S)methylcholic acid (6EMCA or INT-777), which acts as a specific TGR5, but not FXR, agonist [38].

In agreement with our data, Maruyama et al. [33] observed that female $\mathrm{TGR} 5^{-1-}$ mice weigh more. The latter effect of TGR5 was already observed in heterozygous female mice. In agreement with this observation, female $\mathrm{TGR}^{-/-}$mice had a higher fat content, while the lean body weight was unaffected. Also the body composition of the male $\mathrm{TGR}^{-/-}$mice showed a tendency towards increased fat content [33]. Interestingly, in the TGR5 $5^{-/}$ mice line that we generated in our laboratory, body weight was also significantly increased in males (K.S. and J.A., unpubl. data). These two studies contrast with another publication [39], which did not report an effect of the absence of TGR 5 on body weight. This difference may very well be explained by different diets or by other differences in animal experimental conditions in this specific study. Furthermore, the mere absence of a receptor, as in the TGR $5^{-1-}$ mice, should not necessary translate in the opposite phenotype as observed after receptor activation by exogenous ligands.

\section{Effects of TGR5 on Glucose Metabolism and Insulin Sensitivity}

High circulating levels of BAs have been linked to beneficial effects on glucose metabolism, and improved insulin sensitivity and better postprandial glycemic control have been reported $[42,43]$. We have demonstrated that BAs regulate glucose homeostasis through activation of TGR5 [44]. In agreement with the report that TGR5 induces GLP-1 secretion in cultured mouse enteroendocrine STC-1 cells [45], the semisynthetic BA, 6-ethyl23(S)methylcholic acid (6EMCA or INT-777), which is a specific TGR5 agonist, induces GLP-1 secretion in both STC-1 cells as well as in human intestinal NCI-H716 cells, and contributes as such to the effects of TGR5 in glucose homeostasis. Silencing of TGR5 in STC-1 cells using shRNA prevented the secretion of GLP-1, illustrating the involvement of TGR5 in this response. Although the mechanism underlying TGR5-induced GLP-1 secretion is not yet completely established, stimulation of oxidative phosphorylation may be involved. The resulting increase in the ATP/ADP ratio can then induce membrane depolarization and $\mathrm{Ca}^{2+}$ mobilization in a way reminiscent to the cascade of events leading to insulin release in pancreatic $\beta$-cells [38].

Using obese and insulin-resistant mouse models, we have shown that mice with a gain-of-function of TGR5 are more glucose-tolerant, whereas $\mathrm{TGR} 5^{-/-}$mice have impaired glucose clearance. This effect was correlated with a healthier pancreatic islet phenotype in the TGR5 transgenic mice, and is at least partly explained by the tonic increase of GLP-1 secretion by TGR5 [44]. It was recently reported by Poole et al. [37] that TGR5 is also expressed in inhibitory motor neurons and modulates intestinal motility. This effect of TGR 5 could be related to GLP-1 induction, which is also known to inhibit intestinal motility [46]. In apparent contrast to these observations are the findings in a recent study with independently generated $\mathrm{TGR}^{-/-}$mice, demonstrating that female and male chow-fed TGR $5^{-/-}$mice show improved insulin sensitivity [39]. However, it was also shown in this study that male $\mathrm{TGR}^{-1-}$ mice on a high-fat diet are insulinresistant, which is in agreement with our findings. Other evidence that TGR5 activation is beneficial with regard to diabetes comes from the observation that the triterpenoid oleanolic acid, a natural TGR5 agonist, also improves glucose homeostasis [47].

\section{TGR5 Modulates Immune Response}

One of the initial studies on TGR5 examined its role in immune cells and linked TGR5 to the immunomodulatory properties of BAs [30]. This action of TGR5 is relevant, as low-grade inflammation contributes to the development of the metabolic syndrome [48]. TGR5 is highly expressed in monocytes and macrophages, an observation derived from the finding that TGR5 is expressed in human spleen and human CD14+ monocytes, as well as in rabbit alveolar macrophages [30, 35]. In accordance with a report that cAMP inhibits LPS-induced cytokine secretion [49], BAs capable of activating TGR5 were found to increase cAMP production in alveolar macrophages [30]. In addition, BAs reduce the phagocytic activity of these cells and inhibit LPS-induced production of proinflammatory cytokines such as tumor necrosis factor- $\alpha$ (TNF- $\alpha$ ), interleukin (IL)-1 $\alpha$, IL-1 $\beta$, IL- 6 and
40

Dig Dis 2011;29:37-44
Pols/Noriega/Nomura/Auwerx/ Schoonjans 
IL-8 [30]. Human monocytic leukemia THP-1 cells transfected with TGR5 exhibit increased cAMP production and reduced LPS-induced TNF- $\alpha$ expression. These effects were not observed in untransfected THP-1 cells, which express low levels of TGR5, suggesting that these BAs effects are TGR5-dependent [30]. Furthermore, stimulation of isolated rat Kupffer cells with taurolithocholic acid or other TGR5 agonists, such as oleanolic acid, as well as cAMP stimulation reduced the expression of IL-1 $\alpha$, IL-1 $\beta$, IL- 6 and TNF- $\alpha$ following LPS treatment [35].

\section{TGR5 in Liver Function}

Administration of the specific TGR5 agonist INT-777 to high-fat-diet-fed mice reduces liver steatosis and associated hepatocyte damage, as measured by plasma liver enzymes LDH, ASAT and ALAT [38]. This is correlated with decreased plasma triglyceride and nonesterified fatty acid levels. The latter is consistent with the pronounced hepatosteatosis observed in male $\mathrm{TGR}^{-/-}$mice fed a high-fat diet for 8 weeks [39]. These data suggest that activation of TGR5 may prevent nonalcoholic fatty liver disease. The precise mechanisms by which TGR5 induces this effect remain, however, to be dissected. Although TGR5 seems not expressed in hepatocytes, it is detected in many cell types of the liver where it could directly or indirectly modulate liver function and triglyceride metabolism. TGR5 is, for instance, enriched in Kupffer cells, which are resident liver macrophages [35] that can secrete proinflammatory cytokines and as such contribute to the progression of nonalcoholic fatty liver disease [50]. TGR5 has also been shown to modulate microcirculation and fluid secretion in the endothelial and biliary epithelial cells of the liver [34, 41]. Although the increased energy expenditure and GLP-1 secretion following TGR5 activation may very well explain the significant improvement in liver steatosis, it will be challenging to examine whether any of these other cell types in the liver contribute to the protective effects of TGR5 activation against steatosis. Cell-type-specific TGR $5^{-/}$mouse models will be extremely valuable for addressing these questions.

\section{BA Signaling as a Target for Intervention in the Metabolic Syndrome}

\section{BA Signaling as Target for Intervention}

The significance of BAs in human triglyceride metabolism is underlined by findings that BA-binding resins increase VLDL levels and that treatment of cholesterol gallstones in humans with CDCA reduces hypertriglyceridemia [51-53]. In addition to the effects of BAs on human triglyceride metabolism, BAs are correlated to increased insulin sensitivity in humans [42]. Furthermore, patients after bariatric surgery to correct for obesity have higher circulating BA levels, which are positively correlated to peak GLP-1 concentrations [43]. The latter observation was recently confirmed in obese patients who have a decreased postprandial BA response and suboptimal GLP-1 secretion in comparison to subjects of normal weight [54].

The biological properties of TGR5 described in this review, mostly observed in animal models, strongly indicate that TGR5 is linked to the beneficial properties of BAs in humans. This is underlined by the findings that the improvements of BAs on metabolic homeostasis are, amongst others, linked to GLP-1, which is regulated by TGR5 [38, 45]. Furthermore, a recent human genetic study identified an association between the single nucleotide polymorphism rs3731859 within the human TGR5 gene and BMI, waist circumference, intramyocellular lipids and fasting GLP-1 levels [55]. This interesting result warrants further studies to explore the effect of genetic polymorphisms in the TGR5 gene.

\section{Pharmacological Targeting of TGR5}

BAs bind and activate both TGR5 and other (nuclear) receptors, including FXR. The binding pocket for the membrane BA receptor TGR5 and the nuclear BA receptor FXR $\alpha$ is only partially conserved since minor structural modifications on the steroid side chain of BAs can dictate selectivity of the ligand towards TGR5 [56, 57]. Therefore, this unique ligand-binding pocket of TGR5 allows the design of receptor selective ligands, leading to drugs that are able to target TGR5 exclusively.

TGR 5 may be targeted by natural compounds as well as with synthetic agonists. Such TGR 5 agonists include natural BAs, semisynthetic BAs (such as 6-ethyl-23(S) methylcholic acid) [58], bile alcohols and triterpenoid compounds of plant origin, such as oleanolic acid and betulinic acid $[47,59,60]$. Certain steroid hormones also potently activate TGR5 [59], an observation that has been recently confirmed [61]. Significant progress has also been made with the search for synthetic TGR5 agonists, as 3-aryl-4-isoxazolecarboxamides were recently identified to activate TGR5, and found to induce GLP-1 secretion in canines [62]. Furthermore, many drug companies have active TGR 5 programs, which have already resulted in the publication of several patents that describe additional TGR5 ligands. 


\section{Not All That Shines Is Gold - Issues with TGR5}

Recently, several properties of TGR 5 have been described that require further investigation as they could potentially be at the basis of certain side effects. For example, TGR5 has also been linked to epidermal growth factor receptor (EGFR) and c-Jun N-terminal kinase (JNK) signaling pathways in cell culture models, which modulates cell proliferation and apoptosis $[63,64]$. Unfortunately evidence of such an effect was only ascertained in cultured cells and further studies in vivo are definitely required $[63,64]$. TGR5 agonists, including certain steroids [59], were also reported to stimulate radical oxygen species generation in cultured astrocytes [61], which also merits further investigation in vivo. TGR5 activation has been suggested to influence cardiomyocytes as the TGR5-active BAs tauro-CDCA and LCA activated $A K T$ and inhibited glycogen synthase kinase- $3 \beta$ in these cells [65]. In view of the pleiotropic effects of BAs, it will be of interest to assess these effects in TGR $5^{-/}$mice.

In addition to these cellular observations, it has been reported that TGR $5^{-/-}$mice have reduced severity of pancreatitis, induced by direct exposure of the pancreas to high concentrations of taurolithocholic acid 3-sulfate sodium salt [66]. The fact that the pancreas in this study is exposed to very high concentrations of taurolithocholic acid 3-sulfate sodium salt, which are never reached even under pathological conditions, may question the physiological relevance of this study. Finally, the fact that $\mathrm{TGR}^{-/-}$mice were protected against cholelithiasis [31], could imply that TGR 5 agonism predisposes to this condition; however, there are no data to support a negative effect of TGR5 agonists on cholelithiasis. It needs to be stressed that many of these potential liabilities were either observed in cultured cells or in animal models where extremely high nonphysiological concentrations of BAs were used. Further detailed studies using more physiological conditions are therefore required to evaluate the clinical relevance of these observations.

\section{Conclusions and Future Perspectives}

The metabolic studies described above suggest that targeting TGR5 could provide an exciting new therapeutic approach to improve several aspects of the metabolic syndrome. Multiple studies reveal that TGR5 has beneficial effects on body weight in high-fat-diet-fed mice. In addition, TGR5 activation improves glucose homeostasis and reduces hepatic steatosis. Beneficial effects of TGR5 on macrophage-driven inflammation, as evidenced by the reduction of proinflammatory cytokines, may also contribute to a potential positive effect of TGR 5 with regard to the metabolic syndrome. These properties of TGR5 clearly suggest that activation of this GPCR is valuable within the framework of the metabolic syndrome. In view of the established role of BA or BA-like molecules (e.g. dafachronic acids) to promote longevity in yeast [67] and in the worm Caenorhabditis elegans [68], it is also plausible that the various strategies to modulate BA signaling could increase lifespan through their potent hormonal activities that improve metabolism and reduce inflammation - two important contributors that determine lifespan [69].

The development of several novel natural, semisynthetic and synthetic TGR5 agonists is likely to further advance this receptor as a target for the metabolic syndrome. In addition, localized or tissue-specific gene targeting will shed light on ways to increase the efficacy and specificity of drugs that target this BA receptor. Despite the fact that we are convinced targeting BA signaling pathways through TGR 5 holds great promise for the intervention in metabolic diseases, much work still needs to be done, especially to make sure that such compounds are safe.

\section{Acknowledgements}

We thank the Swiss National Science Foundation, ERC, NIH and Ecole Polytechnique Fédérale de Lausanne for funding. T.W.H.P. is supported by a long-term fellowship from FEBS, L.G.N. is supported by a CONACYT fellowship, and M.N. is supported by a fellowship from AXA. We especially acknowledge Mitsuhiro Watanabe, Hiroyuki Sato, and Charles Thomas for their invaluable contributions to many of the studies discussed in this review and the other members of the Auwerx-Schoonjans laboratory over the years for instructive discussions.

\section{Disclosure Statement}

J.A. consults for Intercept, a company that develops bile acid therapeutics.

\footnotetext{
References $>1$ Russell DW: Fifty years of advances in bile acid synthesis and metabolism. J Lipid Res 2009;50(Suppl):S120-S125.

$\checkmark 2$ Russell DW, Setchell KD: Bile acid biosynthesis. Biochemistry 1992;31:4737-4749.

3 Inagaki T, Moschetta A, Lee YK, Peng L, Zhao G, Downes M, Yu RT, Shelton JM, Richardson JA, Repa JJ, Mangelsdorf DJ, Kliewer SA: Regulation of antibacterial defense in the small intestine by the nuclear bile acid receptor. Proc Natl Acad Sci USA 2006; 103:3920-3925.
}

Dig Dis 2011;29:37-44
Pols/Noriega/Nomura/Auwerx/ Schoonjans 
4 Houten SM, Watanabe M, Auwerx J: Endocrine functions of bile acids. EMBO J 2006; 25:1419-1425.

5 Thomas C, Pellicciari R, Pruzanski M, Auwerx J, Schoonjans K: Targeting bile-acid signalling for metabolic diseases. Nat Rev Drug Discov 2008;7:678-693.

6 Seol W, Choi HS, Moore DD: Isolation of proteins that interact specifically with the retinoid $\mathrm{X}$ receptor: two novel orphan receptors. Mol Endocrinol 1995;9:72-85.

$\checkmark 7$ Forman BM, Goode E, Chen J, Oro AE, Bradley DJ, Perlmann T, Noonan DJ, Burka LT, McMorris T, Lamph WW, Evans RM, Weinberger C: Identification of a nuclear receptor that is activated by farnesol metabolites. Cell 1995;81:687-693.

8 Makishima M, Okamoto AY, Repa JJ, Tu H, Learned RM, Luk A, Hull MV, Lustig KD, Mangelsdorf DJ, Shan B: Identification of a nuclear receptor for bile acids. Science 1999; 284:1362-1365.

-9 Parks DJ, Blanchard SG, Bledsoe RK, Chandra G, Consler TG, Kliewer SA, Stimmel JB, Willson TM, Zavacki AM, Moore DD, Lehmann JM: Bile acids: natural ligands for an orphan nuclear receptor. Science 1999; 284:1365-1368.

10 Wang H, Chen J, Hollister K, Sowers LC, Forman BM: Endogenous bile acids are ligands for the nuclear receptor FXR/BAR. Mol Cell 1999;3:543-553.

-11 Otte K, Kranz H, Kober I, Thompson P, Hoefer M, Haubold B, Remmel B, Voss H, Kaiser C, Albers M, Cheruvallath Z, Jackson D, Casari G, Koegl M, Paabo S, Mous J, Kremoser C, Deuschle U: Identification of farnesoid $\mathrm{X}$ receptor beta as a novel mammalian nuclear receptor sensing lanosterol. Mol Cell Biol 2003;23:864-872.

-12 Xie W, Radominska-Pandya A, Shi Y, Simon CM, Nelson MC, Ong ES, Waxman DJ, Evans RM: An essential role for nuclear receptors SXR/PXR in detoxification of cholestatic bile acids. Proc Natl Acad Sci USA 2001;98: 3375-3380.

13 Staudinger JL, Goodwin B, Jones SA, Hawkins-Brown D, MacKenzie KI, LaTour A, Liu Y, Klaassen CD, Brown KK, Reinhard J, Willson TM, Koller BH, Kliewer SA: The nuclear receptor PXR is a lithocholic acid sensor that protects against liver toxicity. Proc Natl Acad Sci USA 2001;98:3369-3374.

-14 Makishima M, Lu TT, Xie W, Whitfield GK, Domoto H, Evans RM, Haussler MR, Mangelsdorf DJ: Vitamin D receptor as an intestinal bile acid sensor. Science 2002;296: 1313-1316.

15 Goodwin B, Gauthier KC, Umetani M, Watson MA, Lochansky MI, Collins JL, Leitersdorf E, Mangelsdorf DJ, Kliewer SA, Repa JJ: Identification of bile acid precursors as endogenous ligands for the nuclear xenobiotic pregnane X receptor. Proc Natl Acad Sci USA 2003;100:223-228.
16 Schmidt DR, Holmstrom SR, Fon Tacer K, Bookout AL, Kliewer SA, Mangelsdorf DJ: Regulation of bile acid synthesis by fat-soluble vitamins A and D. J Biol Chem 2010.

17 Li T, Chiang JY: Mechanism of rifampicin and pregnane $\mathrm{X}$ receptor inhibition of human cholesterol 7 alpha-hydroxylase gene transcription. Am J Physiol Gastrointest Liver Physiol 2005;288:G74-G84.

18 Gupta S, Stravitz RT, Dent P, Hylemon PB: Down-regulation of cholesterol 7alpha-hydroxylase (CYP7A1) gene expression by bile acids in primary rat hepatocytes is mediated by the c-Jun N-terminal kinase pathway. J Biol Chem 2001;276:15816-15822.

-19 Holt JA, Luo G, Billin AN, Bisi J, McNeill YY, Kozarsky KF, Donahee M, Wang DY, Mansfield TA, Kliewer SA, Goodwin B, Jones SA: Definition of a novel growth factor-dependent signal cascade for the suppression of bile acid biosynthesis. Genes Dev 2003;17: 1581-1591.

20 Qiao D, Stratagouleas ED, Martinez JD: Activation and role of mitogen-activated protein kinases in deoxycholic acid-induced apoptosis. Carcinogenesis 2001;22:35-41.

-21 Dent P, Fang Y, Gupta S, Studer E, Mitchell C, Spiegel S, Hylemon PB: Conjugated bile acids promote ERK1/2 and AKT activation via a pertussis toxin-sensitive mechanism in murine and human hepatocytes. Hepatology 2005;42:1291-1299.

22 Qiao L, Han SI, Fang Y, Park JS, Gupta S, Gilfor D, Amorino G, Valerie K, Sealy L, Engelhardt JF, Grant S, Hylemon PB, Dent P: Bile acid regulation of C/EBPbeta, CREB, and c-Jun function, via the extracellular signalregulated kinase and c-Jun $\mathrm{NH} 2$-terminal kinase pathways, modulates the apoptotic response of hepatocytes. Mol Cell Biol 2003; 23:3052-3066.

23 Goldberg AA, Richard VR, Kyryakov P, Bourque SD, Beach A, Burstein MT, Glebov A, Koupaki O, Boukh-Viner T, Gregg C, Juneau M, English AM, Thomas DY, Titorenko VI: Chemical genetic screen identifies lithocholic acid as an anti-aging compound that extends yeast chronological life span in a TOR-independent manner, by modulating housekeeping longevity assurance processes. Aging (Albany NY) 2010;2:393-414.

24 Pierce KL, Premont RT, Lefkowitz RJ: Seventransmembrane receptors. Nat Rev Mol Cell Biol 2002;3:639-650.

25 Raufman JP, Zimniak P, Bartoszko-Malik A: Lithocholyltaurine interacts with cholinergic receptors on dispersed chief cells from guinea pig stomach. Am J Physiol 1998; 274:G997-G1004.

26 Raufman JP, Chen Y, Zimniak P, Cheng K: Deoxycholic acid conjugates are muscarinic cholinergic receptor antagonists. Pharmacology 2002;65:215-221.

27 Le Y, Murphy PM, Wang JM: Formyl-peptide receptors revisited. Trends Immunol 2002; 23:541-548.
28 Ferrari C, Macchiarulo A, Costantino G, Pellicciari R: Pharmacophore model for bile acids recognition by the FPR receptor. J Comput Aided Mol Des 2006;20:295-303.

-29 Maruyama T, Miyamoto Y, Nakamura T, Tamai Y, Okada H, Sugiyama E, Itadani $\mathrm{H}$, Tanaka K: Identification of membrane-type receptor for bile acids (M-BAR). Biochem Biophys Res Commun 2002;298:714-719.

30 Kawamata Y, Fujii R, Hosoya M, Harada M, Yoshida H, Miwa M, Fukusumi S, Habata Y, Itoh T, Shintani Y, Hinuma S, Fujisawa Y, Fujino M: A G protein-coupled receptor responsive to bile acids. J Biol Chem 2003;278: 9435-9440.

31 Vassileva G, Golovko A, Markowitz L, Abbondanzo SJ, Zeng M, Yang S, Hoos L, Tetzloff G, Levitan D, Murgolo NJ, Keane K, Davis HR Jr, Hedrick J, Gustafson EL: Targeted deletion of Gpbarl protects mice from cholesterol gallstone formation. Biochem J 2006; 398:423-430.

-32 Keitel V, Cupisti K, Ullmer C, Knoefel WT, Kubitz R, Haussinger D: The membranebound bile acid receptor TGR5 is localized in the epithelium of human gallbladders. Hepatology 2009;50:861-870.

33 Maruyama T, Tanaka K, Suzuki J, Miyoshi H, Harada N, Nakamura T, Miyamoto Y, Kanatani A, Tamai Y: Targeted disruption of $\mathrm{G}$ protein-coupled bile acid receptor 1 (Gpbar1/M-Bar) in mice. J Endocrinol 2006; 191:197-205.

-34 Keitel V, Reinehr R, Gatsios P, Rupprecht C, Gorg B, Selbach O, Haussinger D, Kubitz R: The G-protein coupled bile salt receptor TGR5 is expressed in liver sinusoidal endothelial cells. Hepatology 2007;45:695-704.

35 Keitel V, Donner M, Winandy S, Kubitz R, Haussinger D: Expression and function of the bile acid receptor TGR5 in Kupffer cells. Biochem Biophys Res Commun 2008;372: 78-84.

36 Watanabe M, Houten SM, Mataki C, Christoffolete MA, Kim BW, Sato H, Messaddeq N, Harney JW, Ezaki O, Kodama T, Schoonjans K, Bianco AC, Auwerx J: Bile acids induce energy expenditure by promoting intracellular thyroid hormone activation. Nature 2006;439:484-489.

- 37 Poole DP, Godfrey C, Cattaruzza F, Cottrell GS, Kirkland JG, Pelayo JC, Bunnett NW, Corvera CU: Expression and function of the bile acid receptor GpBAR1 (TGR5) in the murine enteric nervous system. Neurogastroenterol Motil 2010;22:814-825, e227e228.

38 Thomas C, Gioiello A, Noriega L, Strehle A, Oury J, Rizzo G, Macchiarulo A, Yamamoto H, Mataki C, Pruzanski M, Pellicciari R, Auwerx J, Schoonjans K: TGR5-mediated bile acid sensing controls glucose homeostasis. Cell Metab 2009;10:167-177. 
-39 Vassileva G, Hu W, Hoos L, Tetzloff G, Yang S, Liu L, Kang L, Davis H, Hedrick J, Lan H, Kowalski T, Gustafson E: Gender-dependent effect of Gpbarl genetic deletion on the metabolic profiles of diet-induced obese mice. J Endocrinol 2010;205:225-232.

-40 Lavoie B, Balemba OB, Godfrey C, Watson CA, Vassileva G, Corvera CU, Nelson MT, Mawe GM: Hydrophobic bile salts inhibit gallbladder smooth muscle function via stimulation of GPBAR1 receptors and activation of KATP channels. J Physiol 2010;588: 3295-3305.

-41 Keitel V, Ullmer C, Haussinger D: The membrane-bound bile acid receptor TGR5 (Gpbar-1) is localized in the primary cilium of cholangiocytes. Biol Chem 2010;391:785789.

-42 Shaham O, Wei R, Wang TJ, Ricciardi C, Lewis GD, Vasan RS, Carr SA, Thadhani R, Gerszten RE, Mootha VK: Metabolic profiling of the human response to a glucose challenge reveals distinct axes of insulin sensitivity. Mol Syst Biol 2008;4:214.

-43 Patti ME, Houten SM, Bianco AC, Bernier R, Larsen PR, Holst JJ, Badman MK, MaratosFlier E, Mun EC, Pihlajamaki J, Auwerx J, Goldfine AB: Serum bile acids are higher in humans with prior gastric bypass: potential contribution to improved glucose and lipid metabolism. Obesity (Silver Spring) 2009;17: 1671-1677.

-44 Thomas C, Auwerx J, Schoonjans K: Bile acids and the membrane bile acid receptor TGR5 - connecting nutrition and metabolism. Thyroid 2008;18:167-174.

-45 Katsuma S, Hirasawa A, Tsujimoto G: Bile acids promote glucagon-like peptide-1 secretion through TGR5 in a murine enteroendocrine cell line STC-1. Biochem Biophys Res Commun 2005;329:386-390.

- 46 Tolessa T, Gutniak M, Holst JJ, Efendic S, Hellstrom PM: Inhibitory effect of glucagonlike peptide-1 on small bowel motility. Fasting but not fed motility inhibited via nitric oxide independently of insulin and somatostatin. J Clin Invest 1998;102:764-774.

$\checkmark 47$ Sato H, Genet C, Strehle A, Thomas C, Lobstein A, Wagner A, Mioskowski C, Auwerx J, Saladin R: Anti-hyperglycemic activity of a TGR5 agonist isolated from Olea europaea. Biochem Biophys Res Commun 2007;362: 793-798.

-48 Olefsky JM, Glass CK: Macrophages, inflammation, and insulin resistance. Annu Rev Physiol 2010;72:219-246.

49 Yoshimura T, Kurita C, Nagao T, Usami E, Nakao T, Watanabe S, Kobayashi J, Yamazaki F, Tanaka H, Inagaki N, Nagai H: Inhibition of tumor necrosis factor-alpha and interleukin-1-beta production by beta-adrenoceptor agonists from lipopolysaccharidestimulated human peripheral blood mononuclear cells. Pharmacology 1997;54:144152.
50 Baffy G: Kupffer cells in non-alcoholic fatty liver disease: the emerging view. J Hepatol 2009;51:212-223.

51 Grundy SM, Ahrens EH Jr, Salen G: Interruption of the enterohepatic circulation of bile acids in man: comparative effects of cholestyramine and ileal exclusion on cholesterol metabolism. J Lab Clin Med 1971;78:94121.

52 Nestel PJ, Poyser A: Changes in cholesterol synthesis and excretion when cholesterol intake is increased. Metabolism 1976;25:15911599.

53 Angelin B, Einarsson K, Hellstrom K: Effect of cholestyramine on bile acid kinetics in patients with portal cirrhosis of the liver. Evidence of a selective defect in the formation of cholic acid. Am J Dig Dis 1978;23:1115-1120.

54 Glicksman C, Pournaras DJ, Wright M, Roberts R, Mahon D, Welbourn R, Sherwood R, Alaghband-Zadeh J, le Roux CW: Postprandial plasma bile acid responses in normal weight and obese subjects. Ann Clin Biochem 2010;47:482-484.

55 Mussig K, Staiger H, Machicao F, Machann J, Schick F, Schafer SA, Claussen CD, Holst JJ, Gallwitz B, Stefan N, Fritsche A, Haring HU: Preliminary report: genetic variation within the GPBAR1 gene is not associated with metabolic traits in white subjects at an increased risk for type 2 diabetes mellitus. Metabolism 2009;58:1809-1811.

56 Pellicciari R, Sato H, Gioiello A, Costantino G, Macchiarulo A, Sadeghpour BM, Giorgi G, Schoonjans K, Auwerx J: Nongenomic actions of bile acids. Synthesis and preliminary characterization of 23- and 6,23-alkyl-substituted bile acid derivatives as selective modulators for the G-protein coupled receptor TGR5. J Med Chem 2007;50:4265-4268.

57 Macchiarulo A, Gioiello A, Thomas C, Massarotti A, Nuti R, Rosatelli E, Sabbatini P, Schoonjans K, Auwerx J, Pellicciari R: Molecular field analysis and 3D-quantitative structure-activity relationship study (MFA 3D-QSAR) unveil novel features of bile acid recognition at TGR5. J Chem Inf Model 2008;48:1792-1801.

58 Pellicciari R, Gioiello A, Macchiarulo A, Thomas C, Rosatelli E, Natalini B, Sardella R, Pruzanski M, Roda A, Pastorini E, Schoonjans K, Auwerx J: Discovery of 6alpha-ethyl-23(S)-methylcholic acid (SEMCA, INT-777) as a potent and selective agonist for the TGR5 receptor, a novel target for diabesity. J Med Chem 2009;52:79587961.

59 Sato H, Macchiarulo A, Thomas C, Gioiello A, Une M, Hofmann AF, Saladin R, Schoonjans K, Pellicciari R, Auwerx J: Novel potent and selective bile acid derivatives as TGR5 agonists: biological screening, structure-activity relationships, and molecular modeling studies. J Med Chem 2008;51: 1831-1841.
60 Genet C, Strehle A, Schmidt C, Boudjelal G, Lobstein A, Schoonjans K, Souchet M, Auwerx J, Saladin R, Wagner A: Structure-activity relationship study of betulinic acid, a novel and selective TGR5 agonist, and its synthetic derivatives: potential impact in diabetes. J Med Chem 2010;53:178-190.

61 Keitel V, Gorg B, Bidmon HJ, Zemtsova I, Spomer L, Zilles K, Haussinger D: The bile acid receptor TGR5 (Gpbar-1) acts as a neurosteroid receptor in brain. Glia 2010;58: 1794-1805.

62 Evans KA, Budzik BW, Ross SA, Wisnoski DD, Jin J, Rivero RA, Vimal M, Szewczyk GR, Jayawickreme C, Moncol DL, Rimele TJ, Armour SL, Weaver SP, Griffin RJ, Tadepalli SM, Jeune MR, Shearer TW, Chen ZB, Chen L, Anderson DL, Becherer JD, De Los Frailes M, Colilla FJ: Discovery of 3-aryl-4-isoxazolecarboxamides as TGR5 receptor agonists. J Med Chem 2009;52:7962-7965.

63 Yang JI, Yoon JH, Myung SJ, Gwak GY, Kim W, Chung GE, Lee SH, Lee SM, Kim CY, Lee HS: Bile acid-induced TGR5-dependent c-Jun-N terminal kinase activation leads to enhanced caspase 8 activation in hepatocytes. Biochem Biophys Res Commun 2007; 361:156-161.

64 Yasuda $\mathrm{H}$, Hirata S, Inoue K, Mashima H, Ohnishi H, Yoshiba M: Involvement of membrane-type bile acid receptor M-BAR/TGR5 in bile acid-induced activation of epidermal growth factor receptor and mitogen-activated protein kinases in gastric carcinoma cells. Biochem Biophys Res Commun 2007;354: 154-159.

65 Desai MS, Shabier Z, Taylor M, Lam F, Thevananther S, Kosters A, Karpen SJ: Hypertrophic cardiomyopathy and dysregulation of cardiac energetics in a mouse model of biliary fibrosis. Hepatology 2010;51:2097-2107.

- 66 Perides G, Laukkarinen JM, Vassileva G Steer ML: Biliary acute pancreatitis in mice is mediated by the G-protein-coupled cell surface bile acid receptor Gpbarl. Gastroenterology 2010;138:715-725.

67 Motola DL, Cummins CL, Rottiers V, Sharma KK, Li T, Li Y, Suino-Powell K, Xu HE, Auchus RJ, Antebi A, Mangelsdorf DJ: Identification of ligands for DAF-12 that govern dauer formation and reproduction in C. elegans. Cell 2006;124:1209-1223.

68 Gerisch B, Rottiers V, Li D, Motola DL, Cummins CL, Lehrach H, Mangelsdorf DJ, Antebi A: A bile acid-like steroid modulates Caenorhabditis elegans lifespan through nuclear receptor signaling. Proc Natl Acad Sci USA 2007;104:5014-5019.

69 Houtkooper RH, Williams RW, Auwerx J: Metabolic networks of longevity. Cell 2010; 142:9-14.

Pols/Noriega/Nomura/Auwerx/ Schoonjans 